\section{Ferramenta de apoio para o Design de Mídia e Interatividade no contexto de um Book App Infantil}

\author{
Support Tool for Media Design and Interactivity in the Context of a Children Book \\ App
}

\author{
Bruna Bertolazi Maritan, Berenice S. Gonçalves, Deglaucy Jorge Teixeira
}

book app infantil, livro digital infantil, design de mídias, interatividade

\begin{abstract}
A partir do surgimento das tecnologias digitais o livro infantil passou a utilizar o formato aplicativo, que possibilita agregar multimídia e interatividade. Por essa razão, vem sendo explorado para esse público. Porém, os conhecimentos do design tradicional não são suficientes para atender as demandas desse contexto de projeto. Faz-se necessário buscar ferramentas de apoio para o design das mídias e interatividade respeitando premissas do book app infantil, considerando que esses recursos tecnológicos devem ajudar a contar a história sem desviar a atenção da narrativa. Tendo em vista essa finalidade, o presente artigo objetivou testar a Matriz LIDI, originalmente concebida para fins de análise, como uma ferramenta de apoio para o design das mídias e interatividade aplicando-a em um projeto real. $\mathrm{O}$ foco central dessa ferramenta está em considerar o potencial hipermidiático do book app infantil relacionado às possibilidades tecnológicas com a narrativa. A aplicação da Matriz foi realizada em um workshop. A partir dos resultados desse evento, a equipe de projeto construiu a escaletta e storyboard para organizar as informações necessárias para preenchimento. Concluiu-se que a ferramenta se mostrou útil para a finalidade proposta. Assim, além da função de análise ela pode auxiliar no projeto do livro digital interativo infantil.
\end{abstract}

children book app, interactive children book, media design, interactivity

With the advent of digital technologies, the children's book began to use the app format, which enables the addition of multimedia and interactivity. For this reason, it has been explored for this audience. However, traditional design knowledge is not enough to support the demands of this project context. It is necessary to seek support tools for media design and interactivity respecting the premise of the children's book app, considering that these technological resources should help tell the story without diverting attention from the narrative. With this purpose in mind, this article aims to test the Matriz LIDI, originally created for analysis purposes, as a support tool for the design of the media and interactivity by applying it in a real project. The central focus of this tool is to consider the hypermiditic potential of the children's book app related to the technological possibilities with the narrative. The application of the Matriz was done in a workshop. With the results of this event, the project team built the escaletta and storyboard to organize the information needed to complete. It was concluded that the tool proved to be useful for the proposed purpose. Therefor, in addition to the analysis function, it can assist in the design of the digital interactive children's book.

\section{Introdução}

O surgimento das tecnologias digitais gerou mudanças para o design do livro que passou a utilizar também o formato digital. Em especial para o universo infantil os livros digitais interativos têm se mostrado atrativos por apresentar outra dinâmica de leitura. Eles vêm sendo produzidos no formato book app, livro aplicativo, que possibilita agregar multimídia e interatividade.

Porém, o design ainda está se adaptando a esses novos formatos. Os conhecimentos tradicionais do design editorial não são suficientes para atender às especificidades do desenvolvimento de um book app infantil. É preciso incluir no processo o design das mídias e interação.

Por exemplo, para Haslam (2007), o designer editorial adota quatro abordagens: documentação, análise, conceito e expressão. A documentação é o ponto de partida do livro, que terá seu conteúdo manipulado pelo designer. A abordagem analítica objetiva encontrar a

Anais do 8 CIDI e 8 CONGIC

Guilherme Santa Rosa; Cristina Portugal (orgs.)

Sociedade Brasileira de Design da Informação - SBDI

Natal | Brasil | 2017

ISBN 978-85-212-1305-5
Proceedings of the $8^{\text {th }}$ CIDI and $8^{\text {th }}$ CONGIC

Guilherme Santa Rosa; Cristina Portugal (orgs.)

Sociedade Brasileira de Design da Informação - SBDI

Natal| Brazil | 2017

ISBN 978-85-212-1305-5 
estrutura do conteúdo, identificar os padrões para classificá-los e hierarquizar a informação. Já a abordagem expressiva é movida pelas emoções de modo a informá-las ao leitor por meio do design. A abordagem conceitual busca o conceito-base de onde possa tirar conexões e ideias. Porém, essas abordagens não prevêem a adequação das tecnologias digitais para o livro.

Nesse sentido, considera-se que o design do book app, e este estudo especificamente, está alinhado ao design da informação, pois, busca viabilizar a organização dos elementos constitutivos do livro digital infantil em sua totalidade. Para Frascara (2011), o processo de design da informação acontece em dois momentos: organização da informação, abrangendo conteúdo e suas unidades de sentido, texto e ilustração e, em um segundo momento, planejamento e implementação da sua apresentação visualmente. Para isso, faz-se necessário habilidades e conhecimentos para processar, organizar e apresentar a informação tanto em sua forma linguística quanto não linguística.

Sendo assim, este artigo procurou apresentar fundamentos para ampliar o olhar do design sobre a concepção do livro digital interativo infantil em relação às possibilidades das tecnologias digitais. Sobretudo, objetivou-se testar uma ferramenta de apoio ao design de multimídia e interatividade no contexto de um projeto de book app infantil.

\section{Design do Livro infantil e Narrativa Interativa}

O livro infantil na categoria de livro ilustrado é caracterizado por conter mais imagens que texto. O formato aplicativo, por se tratar de um software, agrega mídias e interatividade para contar a história ilustrada. De acordo com Chartier (1998), mesmo apresentando-se em formatos diferentes o objetivo principal do livro é transmitir informação. (TEIXEIRA; MARITAN; GONÇALVES, 2016)

No contexto do book app infantil a principal informação é a história. Para Chatman (1980), o ato de contar a história pode ser denominado pelo termo narrative, que engloba a narração (conteúdo da história - personagens, cenários, acontecimentos) e o discurso (expressão estrutura e mídias). Com base em Pimenta (2010) a Narrativa Visual Interativa é naturalmente visual ou audiovisual e envolve interação com o usuário desde opções de navegação, como avançar e retornar, até imersão total como um personagem da história. (TEIXEIRA, 2015)

De acordo com Miller (2014) a estrutura da narrativa consiste em três blocos, sendo primeiro ato, segundo ato e terceiro ato - começo meio e fim, compondo o drama clássico proposto por Aristóteles para uma história eficaz. Laurel (2014) utilizou o triângulo do alemão Gustav Freytag, crítico e dramaturgo do século XIX, para representar a anatomia das ações dramáticas. Teixeira (2015), explica que o ápice representa o clímax dramático e os lados a evolução e declínio das ações. O eixo horizontal representa uma linha do tempo e o eixo vertical a complicação.

Com base nessas propostas Teixeira (2015) apresenta a estrutura da narrativa combinando os blocos maiores (os três atos) e o arco dramático em blocos menores como mostra a Figura 1. A história inicia no segmento $A$, Exposição, que apresenta os personagens, ambiente e contexto onde as ações vão se desdobrar. É seguido do Acontecimento Inicial, segmento B, onde comumente se dá a ação que conduzirá ao clímax da história, por isso a inclinação acentuada desse segmento. A Ação Crescente, segmento $C$, se dá continuidade à ação do segmento anterior. Nesse momento é revelado o objetivo central do personagem e como ele planeja alcançá-lo. No próximo segmento, D, Crise, há um envolvimento do personagem com seu propósito que vai aumentando conforme a história se encaminha para seu Clímax, segmento $E$, onde ele tem sucesso ou fracasso na busca de seu objetivo. A Ação Decrescente, segmento $\mathrm{F}$, apresenta os acontecimentos em consequência do Clímax. Esse segmento é mais inclinado porque geralmente as situações tendem a serem resolvidas de maneira mais ágil. No segmento G, Desfecho, volta-se à normalidade e se tem a recompensa do protagonista de acordo com o resultado de suas ações. 
Figura 1 - Estrutura adaptada para a narrativa interativa. Fonte: TEIXEIRA, 2015.

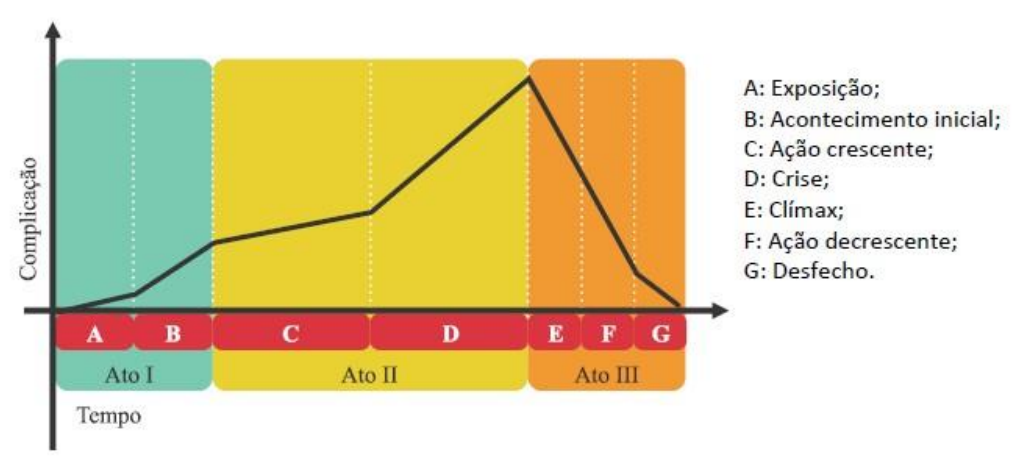

\section{Matriz LIDI}

A partir dessa estrutura de narrativa Teixeira (2015) desenvolveu a Matriz LIDI, ferramenta de análise criada para relacionar a multimídia e interatividade junto à narrativa levando em conta 0 potencial hipermidiático do book app infantil. É dividida entre ficha de conteúdo e preenchimento da Matriz em si.

$\mathrm{Na}$ ficha de conteúdo as cenas da narrativa são separadas para se coletar as informações com o intuito de posteriormente preencher a Matriz de análise. Pode ser feito em forma de escaletta de roteiro audiovisual, separando as cenas de acordo com as ações dramáticas do ponto de vista do protagonista. Neste caso, a escaletta representa os momentos chave da narrativa, organizada em quadros contendo personagem, ação, lugar e tempo. O objetivo é obter uma visão geral do roteiro para construir uma estrutura da narrativa. (TEIXEIRA, 2015)

Na Matriz (Figura 2) essas informações são primeiramente separadas em blocos menores de acordo com o arco dramático e em seguida em três blocos maiores que correspondem aos atos. Analisar as cenas em blocos menores é vantajoso para identificar as mídias e interatividades de cada tela em um nível mais básico.

O preenchimento da Matriz em si começa com o conteúdo dramático que já foi organizado na ficha de conteúdo e consiste nas ações que representam os momentos-chave da narrativa, descrevendo os agentes afetados pelas ações. Para isso os verbos de ação são destacados, de acordo com Greg Roach (apud MILLER, 2014), considerando as frases ativas acima das descritivas. Em seguida é preenchida a "expressão hipermídia" dividida em multimídia (texto, imagem e som) e interatividade. Por último se avalia a coerência como total, parcial ou inexistente. No book app infantil alguns elementos interativos e mídias usadas podem não estar coerentes com o contexto da história e desviar a atenção do leitor. Cada mídia e interação deve ter um porque de existir. (TEIXEIRA, 2015) 


\section{CIDI 2017

Figura 2 - Matriz LIDI original. Fonte: TEIXEIRA, 2015.

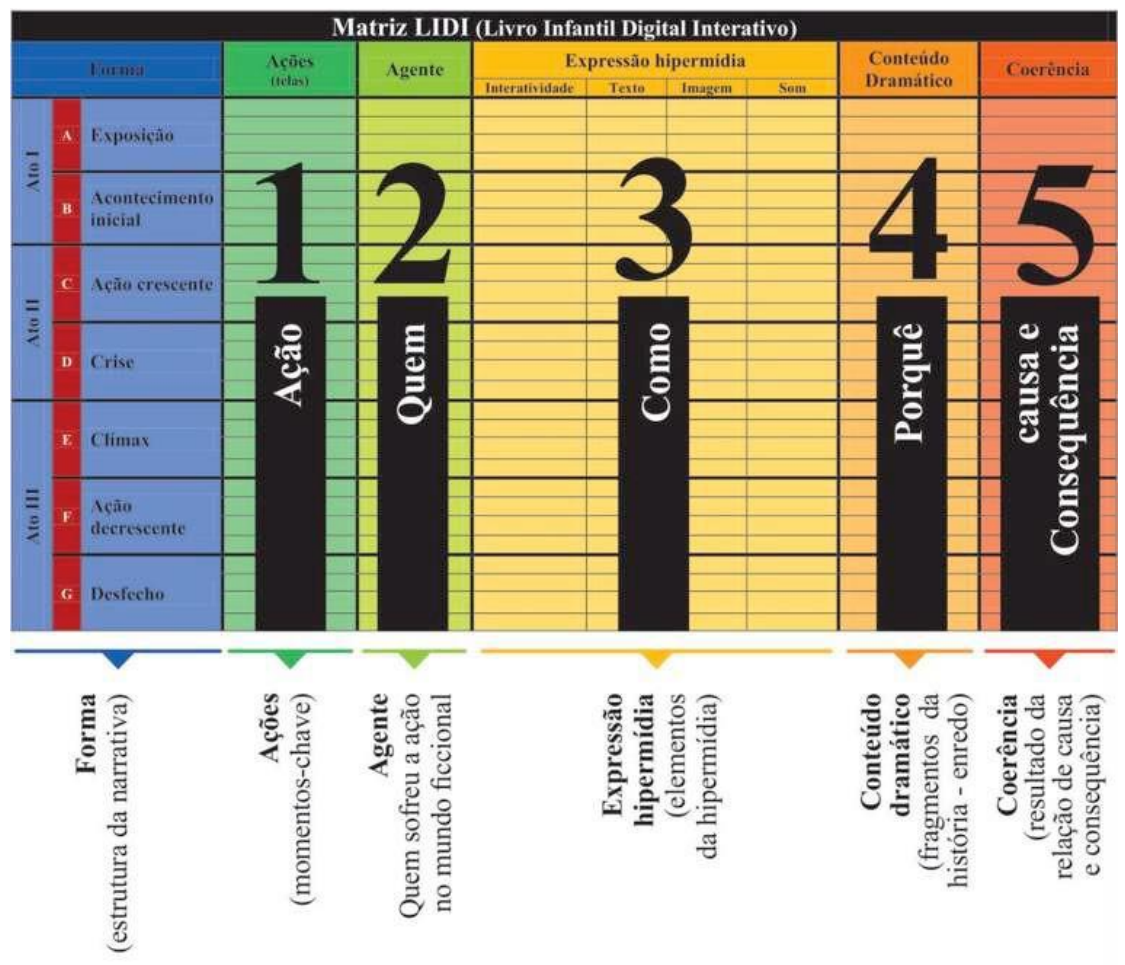

\section{Premissas para um Book App Infantil de qualidade}

A partir de uma investigação por meio de levantamento bibliográfico e critérios utilizados pelo Bologna Ragazzi Digital Awards e Digital Book Awards, premiações mundiais de book apps, elaborou-se uma tabela para esquematizar todas as informações relevantes a boas práticas para o design de book app infantil.

Tabela 1 - Premissas para o book app infantil. Fonte: elaborada pelos autores.

\begin{tabular}{|c|c|c|}
\hline $\mathrm{n} \mathbf{0}^{-}$ & Premissas & Referência \\
\hline 1 & Conteúdo íntegro quanto à disponibilidade após a aquisição; & $\begin{array}{l}\text { BOLOGNARAGAZZI } \\
\text { DIGITAL AWARD, } 2014\end{array}$ \\
\hline \multirow{2}{*}{2} & \multirow{2}{*}{ Créditos e metadados no devido lugar; } & $\begin{array}{l}\text { BOLOGNARAGAZZI } \\
\text { DIGITAL AWARD, } 2014\end{array}$ \\
\hline & & $\begin{array}{l}\text { DIGITAL BOOK } \\
\text { AWARDS, } 2014\end{array}$ \\
\hline 3 & Design (comunicação clara e eficaz); & $\begin{array}{l}\text { DIGITAL BOOK } \\
\text { AWARDS, } 2014\end{array}$ \\
\hline 4 & Consistência (hierarquia da informação e funcionamento do todo); & $\begin{array}{l}\text { DIGITAL BOOK } \\
\text { AWARDS, } 2014\end{array}$ \\
\hline 5 & $\begin{array}{l}\text { Conteúdo (cumpre o que promete - enriquece, ilumina, entretém e satisfaz os } \\
\text { leitores); }\end{array}$ & $\begin{array}{l}\text { DIGITAL BOOK } \\
\text { AWARDS, } 2014\end{array}$ \\
\hline 6 & Links e referências cruzadas de conteúdo; & $\begin{array}{l}\text { DIGITAL BOOK } \\
\text { AWARDS, } 2014\end{array}$ \\
\hline 7 & $\begin{array}{l}\text { Apropriação das possibilidades permitidas pelo ambiente digital (destaque de } \\
\text { texto, interatividades, conteúdos extras, narrativa não linear, línguas diferentes); }\end{array}$ & (YOKOTA, 2014) \\
\hline 8 & & (YOKOTA, 2014) \\
\hline
\end{tabular}




\begin{tabular}{|c|c|c|}
\hline & $\begin{array}{l}\text { Recursos suplementares devem estar alinhados com a narrativa (como puzzles, } \\
\text { pintura, desenhos, jogos de memória etc); }\end{array}$ & \\
\hline 9 & $\begin{array}{l}\text { Ampliação de possibilidades e formatos (por ex. pensar fora da página, não } \\
\text { trazer metáforas do livro impresso); }\end{array}$ & $\begin{array}{l}\text { BOLOGNARAGAZZI } \\
\text { DIGITAL AWARD, } 2014\end{array}$ \\
\hline 10 & $\begin{array}{l}\text { Equilíbrio com o uso das mídias e interatividade, com opção para não utilizá-las } \\
\text { (botão mudo, por exemplo) }\end{array}$ & $\begin{array}{l}\text { BOLOGNARAGAZZI } \\
\text { DIGITAL AWARD, } 2014\end{array}$ \\
\hline \multirow[b]{2}{*}{11} & \multirow{2}{*}{$\begin{array}{l}\text { Inovação e adequação da narrativa ao formato digital e ao dispositivo (mídias, } \\
\text { narração, efeitos visuais e sonoros); }\end{array}$} & (YOKOTA, 2014) \\
\hline & & $\begin{array}{l}\text { DIGITAL BOOK } \\
\text { AWARDS, } 2014\end{array}$ \\
\hline \multirow[t]{2}{*}{12} & \multirow{2}{*}{$\begin{array}{l}\text { Interatividade deve contribuir para a integridade da narrativa com orientação } \\
\text { clara para o leitor saber como usá-la (colocar imagem ou nome do leitor com } \\
\text { integrante da história, efeitos e interatividades coerentes com o fluxo da história } \\
\text { (leitura mais ativa); }\end{array}$} & $\begin{array}{l}\text { (YOKOTA, 2014) } \\
\text { BOLOGNARAGAZZI } \\
\text { DIGITAL AWARD, } 2014\end{array}$ \\
\hline & & $\begin{array}{l}\text { DIGITAL BOOK } \\
\text { AWARDS, } 2014\end{array}$ \\
\hline 13 & $\begin{array}{l}\text { Recursos significativos ao aprendizado da leitura e do conteúdo em termos } \\
\text { gerais (favorecer o reconhecimento de palavras e aprendizado em diferentes } \\
\text { línguas - escolha da tipografia adequada, destaque de palavras ao serem } \\
\text { narradas, interação com palavras); }\end{array}$ & (YOKOTA, 2014) \\
\hline 14 & Usabilidade (navegação tão intuitiva quanto possível) & $\begin{array}{l}\text { DIGITAL BOOK } \\
\text { AWARDS, } 2014\end{array}$ \\
\hline 15 & $\begin{array}{l}\text { Destaque para pontos interativos (do ponto de vista de uma criança, os itens na } \\
\text { tela devem fazer algo); }\end{array}$ & $\begin{array}{l}\text { BOLOGNARAGAZZI } \\
\text { DIGITAL AWARD, } 2014\end{array}$ \\
\hline 16 & Facilidade de leitura para o leitor emergente. & $\begin{array}{l}\text { BOLOGNARAGAZZI } \\
\text { DIGITAL AWARD, } 2014\end{array}$ \\
\hline
\end{tabular}

Alguns desses apontamentos são comuns à outros tipos de projeto. Outros, entretanto, são específicos ao objeto de estudo deste artigo e, portanto, é interessante destacá-las. As premissas 7 (apropriação das possibilidades permitidas pelo ambiente digital) e 11 (inovação e adequação da narrativa ao formato digital e ao dispositivo) parecem lógicas, mas percebe-se que ainda se está caminhando para encontrar o equilíbrio entre as possibilidades e a maneira adequada de aproveitar o ambiente digital. Por outro lado, algumas heranças do livro impresso persistem, por isso o ítem 9 (ampliação de possibilidades e formatos) lembra que é preciso expandir os horizontes. Os ítens 8 (recursos suplementares devem estar alinhados com a narrativa), 12 (interatividade deve contribuir para a integridade da narrativa com orientação clara para o leitor saber como usá-la) e 13 (recursos significativos ao aprendizado da leitura e do conteúdo em termos gerais) alertam para a essência do livro infantil ilustrado: contar uma história. A interatividade tem a função de ajudar a contar a história e não desviar a atenção com jogos que fogem da narrativa e cenários com objetos que se movem sem razão para tal.

As premissas apontadas tanto incentivam quanto zelam pela adequação do uso das mídias e recursos interativos e, portanto, possui valor de guia para o projeto do book app infantil.

\section{Procedimentos Metodológicos}

A partir da fundamentação apresentada os procedimentos deste estudo se deram por meio da estruturação de um workshop ${ }^{1}$. A etapa de uso da Matriz LIDI, ferramenta apresentada para o 
design das mídias e interação para o book app em questão, se deu a partir das seguintes etapas:

1. Fechamento da primeira etapa do projeto do book app infantil intitulado "O vizinho diferente";

2. Planejamento do workshop: definição de data, local e estrutura necessária, convite aos participantes, organização do coffee break definição dos objetivos, temas e roteiros;

3. Execução do workshop: preparação da apresentação da parte teórica, preparação dos materiais necessários para a parte prática (estrofes da história, cartaz do arco dramático), realização do evento;

4. Resultados: organização e documentação dos materiais resultantes do workshop, esquematização desses resultados, discussão e fechamento com a equipe;

5. Aplicação: utilização dos resultados para continuidade do projeto de book app com preenchimento da Matriz LIDI e desenvolvimento de storyboard para definir o design de interação e mídias e posteriormente wireframes e telas finais.

\section{Resultados e Discussões}

\section{Apresentação do Book App "O Vizinho Diferente"}

O book app infantil apresentado como objeto de estudo para este artigo foi desenvolvido dentro do projeto de pesquisa intitulado "Um modelo de fluxo para o design livro digital: intersecções entre o design editorial, design de interação e o design de mídias". (TEIXEIRA, MARITAN, GONÇALVES, 2016)

O texto utilizado intitulado "Um vizinho diferente" foi escrito por Alexandro Bem. A história é contada no formato de Cordel e se passa em um galinheiro habitado por vários ovinhos. Um dia surge um novo morador, Xisto. Ele teve dificuldade em se entrosar com seus vizinhos que estranharam sua aparência e seu jeito esquisito de andar e falar. O clímax começa a se formar quando cai uma chuva torrencial no galinheiro para acalmar a seca. A situação se agrava e só é resolvida quando o ovinho Xisto eclode e se transforma em um dragão, espantando a chuva com suas novas habilidades. A partir desse dia o galinheiro se transforma, pois, seus moradores aprendem a aceitar todos os ovinhos, mesmo os diferentes.

\section{Planejamento}

O workshop foi organizado pelos pesquisadores do projeto. Definiu-se como objetivo maior do evento organizar de forma colaborativa as mídias e interatividades da narrativa "O Vizinho Diferente" por meio da Matriz LIDI. Foi elaborado um roteiro especificando os temas para a apresentação teórica e as atividades práticas descrevendo os materiais e estrutura necessários. Os participantes convidados foram pensados para abranger perfis diversificados de pessoas ligadas a área.

\section{Execução do workshop}

O evento ocorreu no dia 9 de dezembro das $14 \mathrm{~h}$ às $18 \mathrm{~h}$ CCE UFSC - Universidade Federal de Santa Catarina. Compareceram 11 participantes, desde público alvo até pesquisadores da área.

Dividiu-se os trabalhos em dois momentos, o primeiro teórico em forma de palestra e o segundo prático. Iniciou-se com a apresentação dos seguintes conteúdos: evolução das formas de contar histórias, livro digital interativo infantil, exemplares no formato book app, estrutura da narrativa e mídias, narrativa digital interativa, roteiro para narrativa interativa em livro digital infantile (Figura 3). Destaca-se o interesse e envolvimento dos participantes em fazer questionamentos e discutir sobre os temas apresentados. 


\section{CIDI 2017 先

Figura 3 - Telas da apresentação teórica ministrada no evento. Fonte: elaborada pelos autores.

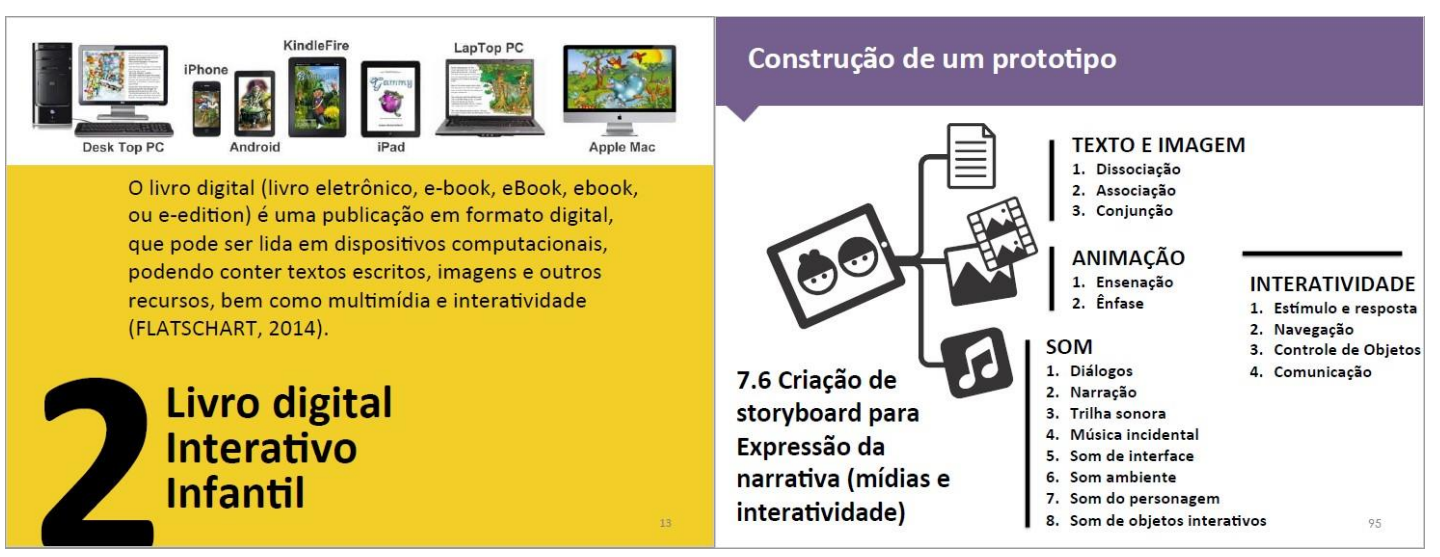

Após intervalo, realizou-se a leitura da história "O Vizinho Diferente" pelo próprio autor. Em seguida, os participantes foram divididos em dois grupos, rosa e amarelo. A atividade consistiu em distribuir as estrofes do texto no arco dramático. Considerou-se cada estrofe equivalente a uma cena. Logo depois, os participantes indicaram quais cenas acreditavam ser significativas explorar a interatividade mediante comportamento do protagonista relacionado a verbos de ação.

Figura 4 - Equipes trabalhando na distribuição das estrofes no arco dramático. Fonte: elaborada pelos autores.

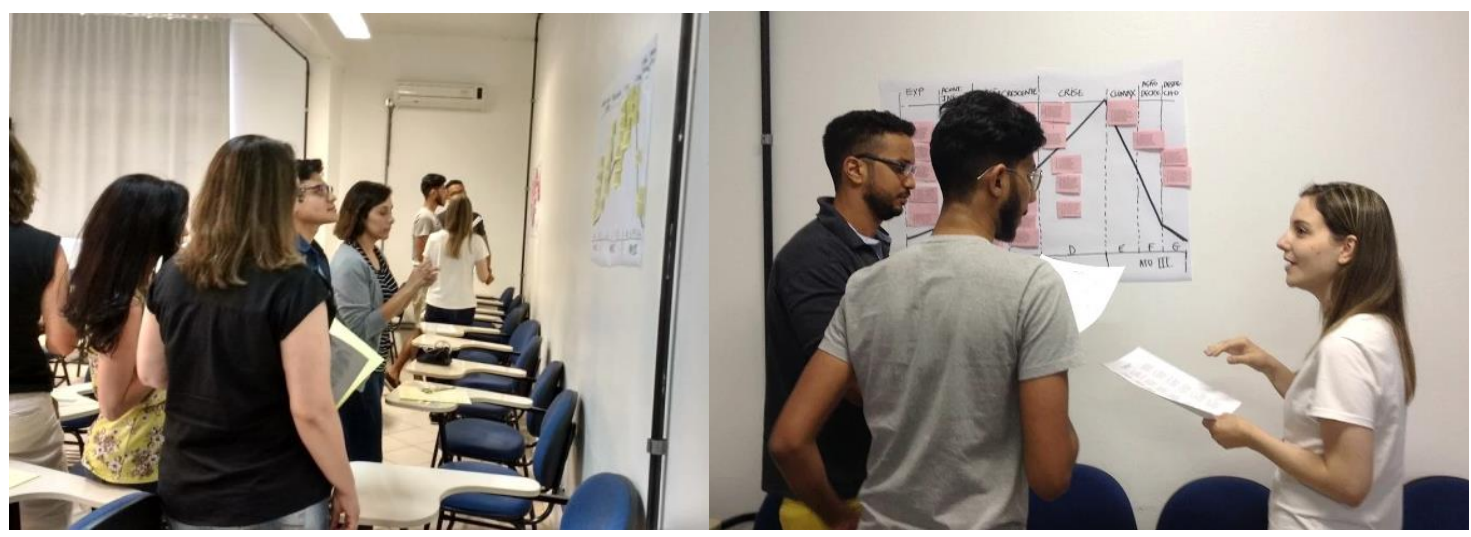

\section{Resultados}

Como resultado do workshop foram obtidos dois gráficos, um de cada equipe, com distribuição das estrofes no arco dramático.

Figura 5 - Gráficos do resultado da distribuição das duas equipes. Fonte: elaborado pela equipe de projeto.

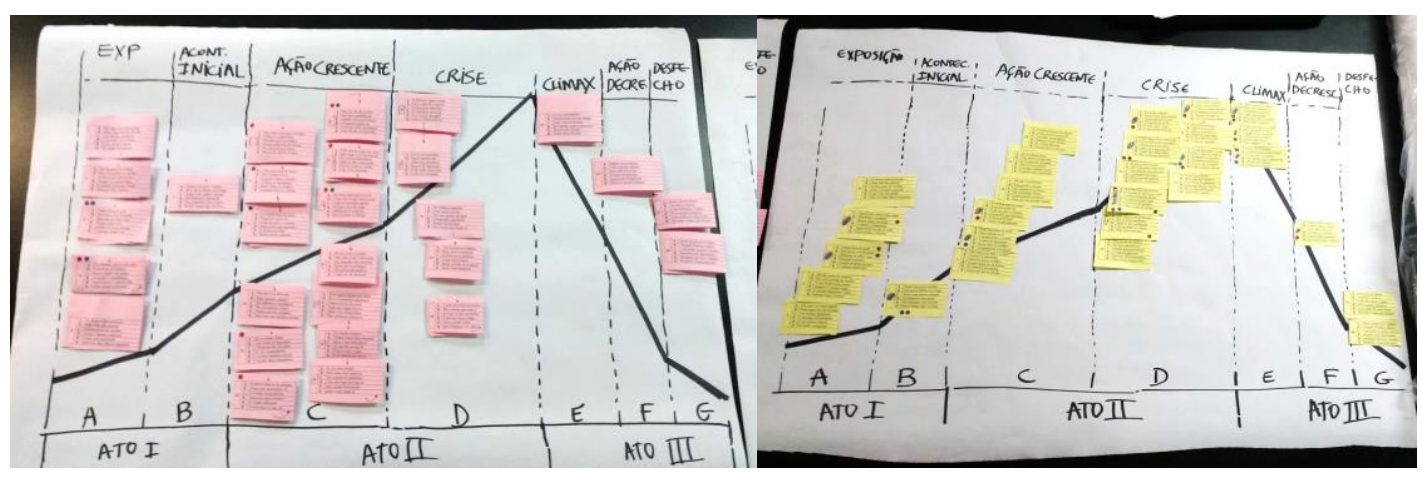




\section{CIDI 2017

A história contém 28 estrofes. As duas equipes distribuíram as cenas da mesma forma nos seguintes segmentos: exposição, acontecimento inicial, ação decrescente e desfecho. As diferenças ocorreram das cenas 13 à 24, sendo que a equipe rosa considerou da 13 a 19 ação crescente e de 20 a 24 crise, sendo 25 o clímax. Já a equipe amarela considerou da cena 13 a 22 crise e 23 a 24 clímax. Portanto, foram distribuídas da mesma forma: exposição do 1 ao 5 , acontecimento inicial 6, ação decrescente 26, desfecho 27 e 28. Diferenças: ação crescente rosa 7 ao 19 amarelo 7 ao 12, crise rosa 20 ao 24 amarelo 13 ao 22, clímax rosa 25 amarelo 23 ao 25.

Figura 6 - Compilação da distribuição das estrofes na estrutura da narrativa. Fonte: elaborada pelos autores.

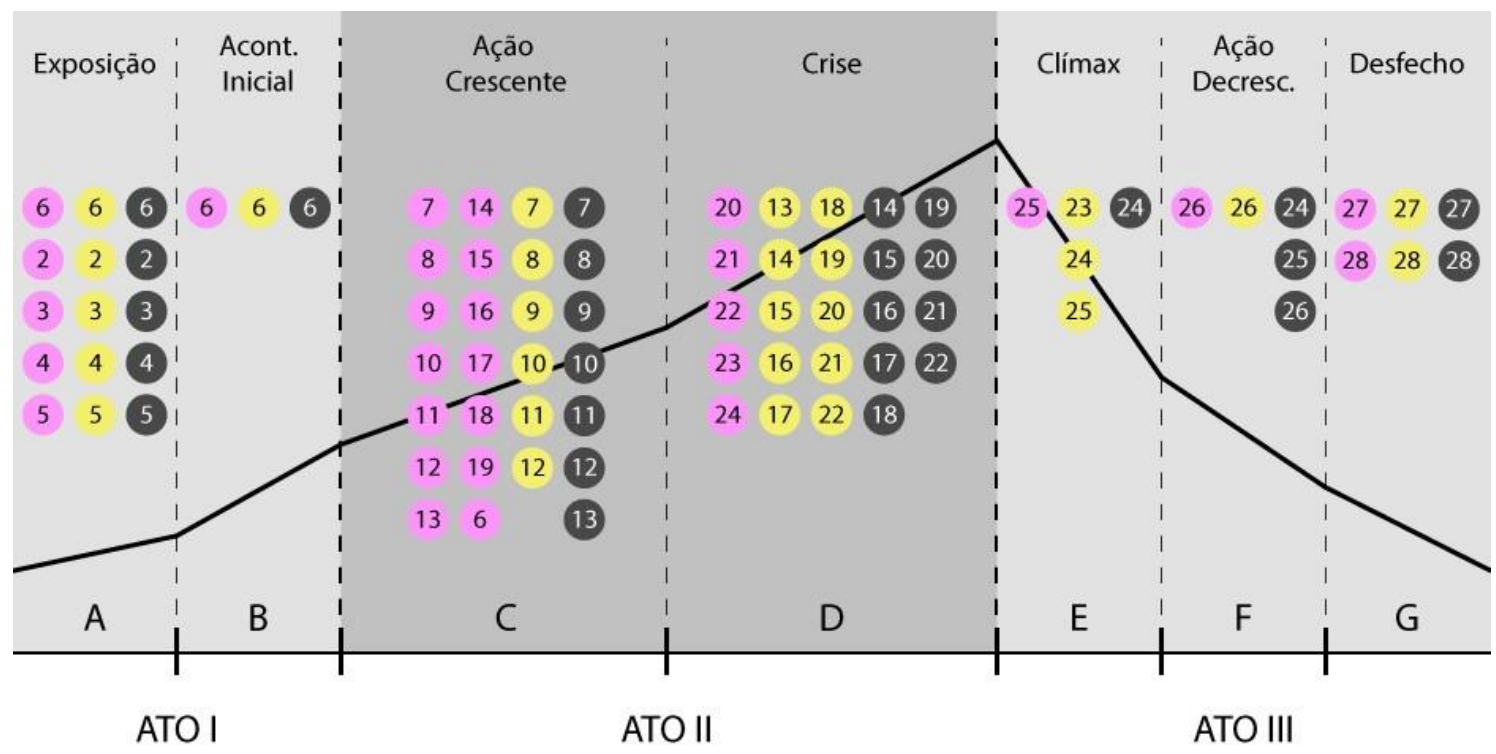

Legenda
(1) Equipe Rosa
1 Equipe Amarela
(1) Distribuição Final

Com base nesses resultados a equipe de projeto determinou a seguinte distribuição: cena 13 na ação crescente, as cenas 14 a 22 como crise, a 23 no clímax e a 24 a 26 na ação decrescente.

\section{Aplicação dos resultados do workshop}

Partiu-se então para a elaboração da ficha de conteúdo em forma de escaletta. Nessa etapa a equipe concluiu que algumas estrofes poderiam ser omitidas e selecionou a princípio 16 das 24 cenas com as ações dramáticas que representavam os momentos chave da narrativa. Cabe esclarecer que o conteúdo das outras estrofes não foi descartado totalmente, mas serviu para entendimento da história e construção da estrutura da narrativa. Indicou-se para cada cena personagens, ação, lugar e tempo de acordo com cada momento chave destacando também os verbos de ação. 


\section{CIDI $2017 \quad 8$ th

Figura 7 - Escaletta desenvolvida para o projeto do book app "O Vizinho Diferente". Fonte: elaborada pelos autores.

\begin{tabular}{|c|c|c|}
\hline 1. Exposiçàa 1 & 2. Exposiçăo 2 & 3. Exposiçäo 3 \\
\hline O galinheiro & A escola de ovinhos & $\begin{array}{l}\text { Ovinhos BRINCAM no pátio } \\
\text { Bola de gude, bambolê, cabra-cega, maculelê, } \\
\text { perna-de-pau, samba lelê, malabares, ciranda, } \\
\text { pula corda. }\end{array}$ \\
\hline apresentaclo $x$ & ambiente da histidria $x$ & brincadeiras no patio $x$ \\
\hline 4. Ovinho novato chega no gafinheirn & 5. Tenta fazer amizado & 6. Medo de Xisto \\
\hline Novo vizinho ESTÁ isclalo & $\begin{array}{l}\text { Xisto E excluido: } \\
\text { Ovinhos se AFASTAM de Xisto }\end{array}$ & $\begin{array}{l}\text { Ovinhos ESCONDEM-se } \\
\text { visisto FICA só no pátio }\end{array}$ \\
\hline a chegade de viato $x$ & aproivimaclio de xisto $x$ & xisto solitivio $x$ \\
\hline 7. Chuva torrencial & 8. Busca de abrigo & 9. Xisto machucado \\
\hline $\begin{array}{l}\text { CAI muita chuva } \\
\text { ovinhos CORREM }\end{array}$ & Xisto TENTA ENTRAR no galinheiro & $\begin{array}{l}\text { Ovirhos EMPURAM Xisto na chaminé } \\
\text { TENTAM loca-lo }\end{array}$ \\
\hline temporal $x$ & busca de abripo $\times$ & viato machucado $x$ \\
\hline 10. Socorro ao Xisto & 11. Galinheiro cai & 12. Transformaçào de Xasto \\
\hline Ovinhos CARREGAM Xisto & $\begin{array}{l}\text { Galinheiro CAI } \\
\text { Ovinhos LEVADOS pela água }\end{array}$ & Xisto QUEBRA a casca \\
\hline socorro $x$ & enchente $x$ & transformecilo $x$ \\
\hline 13. ODragẫo & 14. A Balvaç5o & \\
\hline Xisto TRANSFORMA-se em Dragảo & Xisto Draglo TRAZ o Sol & \\
\hline o dracle $x$ & a salvaclo $x$ & \\
\hline 15. A reconstruçalo & 16. Novos moradores & \\
\hline Xisto Dragāo AJUDA a CONSTRUIR galinheiro & Novos alunos CHEGAM no galinheiro & \\
\hline a moconatruclio $x$ & novos alunas $x$ & \\
\hline
\end{tabular}

Após a escaletta, antes da alimentação da Matriz foi construído um storyboard que, diferente do seu formato tradicional, teve como objetivo organizar as mídias e interação que poderiam ser exploradas em cada tela. Não estava prevista a coleta dessas informações em qualquer momento antes preenchimento da Matriz. Esclarecendo, se o objetivo da escaletta foi organizar o conteúdo dramático a ser preenchido nas primeiras colunas da Matriz, o storyboard teve como objetivo organizar a coluna de expressão hipermídia que consiste na segunda etapa de preenchimento da Matriz.

O storyboard foi construído categorizando as mídias e interatividade em: interatividade, animação, som e relação texto $x$ imagem.

Figura 8 - Storyboard da multimídia e interação. Fonte: elaborado pelos autores. 


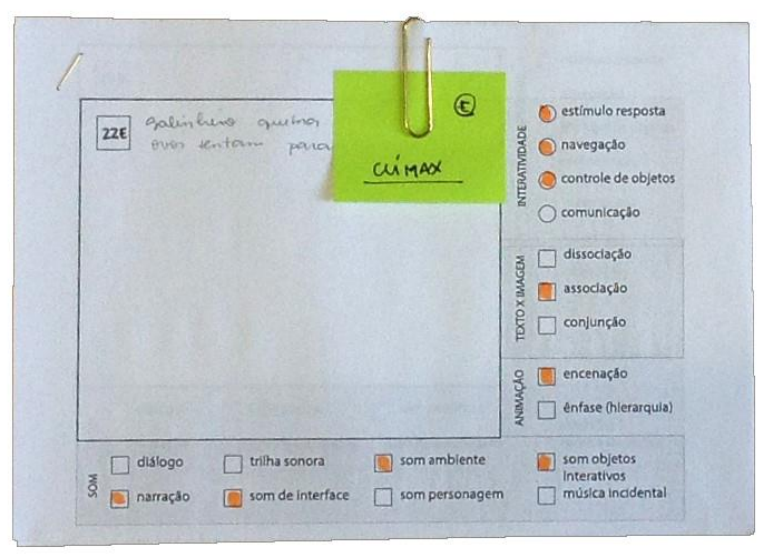

As categorias para a interatividade eram: estímulo resposta, navegação, controle de objetos, e comunicação. Miller (2014) propôs seis tipos de interatividade, sendo quatro delas utilizadas no storyboard, pois se enquadravam nas necessidades do book app infantil. Estímulo e resposta corresponde à interatividade como um clique que aciona alguma função. Navegação é a interatividade que permite navegar no aplicativo, como passar de uma tela à outra. $\mathrm{O}$ controle de objetos consiste na possibilidade de controlar e mover objetos na tela. Comunicação é a interatividade que possibilita a comunicação entre os personagens por meio de voz, menus de diálogo ou ação do usuário.

Para a relação texto $x$ imagem as opções eram: dissociação, associação e conjunção. De acordo com Linden (2011) a relação de dissociação é a alternância de texto e página contendo imagem. O ritmo de leitura se torna mais lento devido à essa alternância de leitura de texto e de imagem. $\mathrm{Na}$ associação texto e imagem se integram em um único enunciado, mas as mensagens sao entendidas separadamente. Por fim, na dissociação texto e imagem são compostos de pequenos trechos de texto organizados próximos às imagens. Percebeu-se que para todas as telas a relação selecionada foi associação.

Para a animação as opções eram encenação e ênfase (hierarquia). Seguindo as ideias de Linden (2011) associadas à imagem fixa no livro ilustrado entendeu-se encenação como o enquadramento da cena com os elementos interativos apresentados claramente e integralmente. O que caracteriza a ênfase é o destaque de alguma informação principal através de algum recurso como tamanho, contraste e outros.

Já para o som as possibilidades eram: diálogo, trilha sonora, som ambiente, som de objetos interativos, narração, som de interface, som de personagem, música incidental. Em uma história audiovisual, segundo Horowitz (2014), o som pode assumir duas funções, a saber: som diegético e som não-diegético. Som diegético: é o som cujas fontes estão presentes na cena, dentro da narrativa, de maneira explícita ou implícita, tais como: diálogos dos personagens, som ambiente e som dos personagens. Som não-diegético: é o som que não se origina dentro da história, como: a voz do narrador, efeitos de som (som de interface e objetos interativos), trilha sonora - música tema com caráter descritivo vinculada a ação por seus aspectos rítmicos como se estivesse comentando as imagens da cena e música incidental - música responsável por trazer maior dramaticidade a cena (DE OLIVEIRA SOBREIRA, 2015).

\section{Preenchimento da Matriz LIDI}

Chegou-se então o momento do preenchimento da Matriz LIDI. Iniciou-se inserindo as informações já esquematizadas na escaletta enumerando as telas e descrevendo para cada uma os verbos de ação, os agentes da ação e as estrofes correspondentes. Depois passou-se para a "expressão hipermídia" transferindo as informações já pensadas no storyboard para a Matriz. Por último avaliou-se a coerência entre os elementos interativos e mídias em relação à história. 


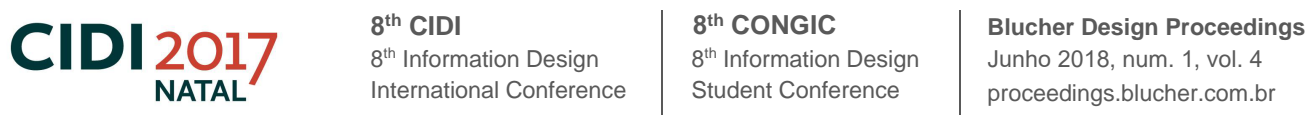

Tabela 2 - Matriz LIDI preenchida para o projeto do book app "O Vizinho Diferente". Fonte: elaborada pelos autores.

\begin{tabular}{|c|c|c|c|c|c|c|c|c|c|c|}
\hline \multirow{2}{*}{$\begin{array}{l}\text { OO } \\
\frac{1}{4}\end{array}$} & \multirow{2}{*}{ 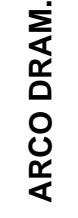 } & \multirow{2}{*}{ 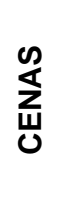 } & \multirow{2}{*}{ AÇÕES } & \multirow{2}{*}{ 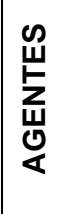 } & \multirow{2}{*}{ 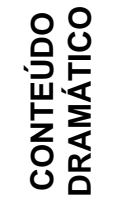 } & \multicolumn{4}{|c|}{ EXPRESSÃO HIPERMÍDIA } & $\overleftarrow{c}$ \\
\hline & & & & & & $\begin{array}{l}\text { INTERA- } \\
\text { TIVIDADE }\end{array}$ & $\begin{array}{l}\text { TEXTO X } \\
\text { IMAGEM }\end{array}$ & ANIMAÇÃO & som & 0 \\
\hline \multirow{4}{*}{ I } & \multirow{3}{*}{ 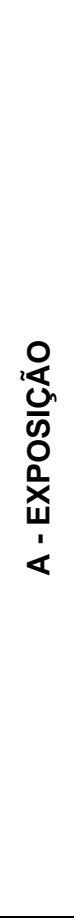 } & 1 & $\begin{array}{l}\text { ovinhos } \\
\text { indo brincar }\end{array}$ & 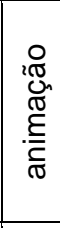 & $\begin{array}{c}\text { estrofes } \\
1 \text { e } 2\end{array}$ & navegação & associação & encenação & $\begin{array}{c}\text { narração - } \\
\text { trilha sonora } \\
\text { - som de } \\
\text { interface - } \\
\text { som } \\
\text { ambiente } \\
\end{array}$ & 要 \\
\hline & & 2 & $\begin{array}{l}\text { jogar - } \\
\text { encantar - } \\
\text { brincar - } \\
\text { dançar - } \\
\text { andar - } \\
\text { cantar }\end{array}$ & 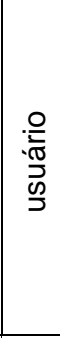 & $\begin{array}{c}\text { estrofe } \\
3\end{array}$ & $\begin{array}{c}\text { navegação } \\
\text { - estímulo } \\
\text { resposta }\end{array}$ & associação & encenação & $\begin{array}{c}\text { narração - } \\
\text { som de } \\
\text { interface - } \\
\text { som } \\
\text { ambiente - } \\
\text { som de } \\
\text { personagens } \\
\text { - som de } \\
\text { objetos } \\
\end{array}$ & 要 \\
\hline & & 3 & $\begin{array}{l}\text { equilibarar - } \\
\text { ciranda - } \\
\text { pular }\end{array}$ & 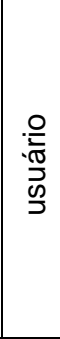 & $\begin{array}{l}\text { estrofes } \\
4 \text { e } 5\end{array}$ & $\begin{array}{l}\text { navegação } \\
\text { - estímulo } \\
\text { resposta }\end{array}$ & associação & encenação & $\begin{array}{c}\text { narração - } \\
\text { som de } \\
\text { interface - } \\
\text { som } \\
\text { ambiente - } \\
\text { som de } \\
\text { personagens } \\
\text { - som de } \\
\text { objetos }\end{array}$ & 要 \\
\hline & 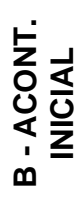 & 4 & $\begin{array}{l}\text { surgir (novo } \\
\text { vizinho) }\end{array}$ & 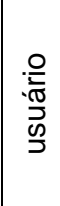 & $\begin{array}{c}\text { estrofe } \\
6\end{array}$ & $\begin{array}{l}\text { navegação } \\
\text { - estímulo } \\
\text { e resposta }\end{array}$ & associação & ênfase & $\begin{array}{l}\text { narração - } \\
\text { som de } \\
\text { interface - } \\
\text { som } \\
\text { ambiente }\end{array}$ & 要 \\
\hline \multirow{3}{*}{ II } & \multirow{3}{*}{ 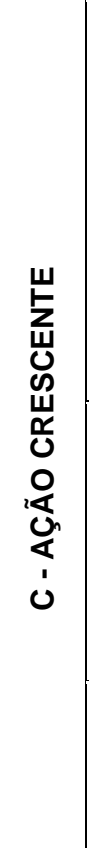 } & 5 & $\begin{array}{l}\text { tentar - } \\
\text { parar }\end{array}$ & $\begin{array}{l}: \text { 은 } \\
\text { 而 } \\
\frac{0}{2}\end{array}$ & $\begin{array}{l}\text { estrofes } \\
7 \text { e } 8\end{array}$ & $\begin{array}{c}\text { navegação } \\
\text { (animação } \\
\text { para } \\
\text { próxima } \\
\text { tela) - } \\
\text { controle } \\
\text { de objetos }\end{array}$ & associação & ênfase & $\begin{array}{c}\text { narração - } \\
\text { som de } \\
\text { interface - } \\
\text { som } \\
\text { ambiente - } \\
\text { som de } \\
\text { personagens } \\
\text { - som de } \\
\text { objetos - } \\
\text { música } \\
\text { incidental } \\
\end{array}$ & 要 \\
\hline & & 6 & $\begin{array}{l}\text { andar } \\
\text { (triste) }\end{array}$ & 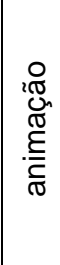 & $\begin{array}{c}\text { estrofes } \\
9,10 \mathrm{e} \\
11\end{array}$ & $\begin{array}{l}\text { navegação } \\
\text { - estímulo } \\
\text { e resposta }\end{array}$ & associação & ênfase & $\begin{array}{c}\text { narração - } \\
\text { som de } \\
\text { interface - } \\
\text { som } \\
\text { ambiente - } \\
\text { som de } \\
\text { personagem }\end{array}$ & 䎡 \\
\hline & & 7 & (ovinhos) & 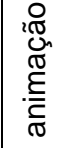 & $\begin{array}{c}\text { estrofe } \\
12\end{array}$ & navegação & associação & encenação & $\begin{array}{l}\text { narração - } \\
\text { som } \\
\text { ambiente }\end{array}$ & 要 \\
\hline
\end{tabular}




\begin{tabular}{|c|c|c|c|c|c|c|c|c|c|c|}
\hline & \multirow{6}{*}{$\begin{array}{l}\frac{山}{\frac{W}{0}} \\
\frac{1}{0} \\
\dot{0}\end{array}$} & 8 & $\begin{array}{c}\text { mudar - } \\
\text { empalidecer } \\
\text { - brincar - } \\
\text { aparecer - } \\
\text { perceber }\end{array}$ & 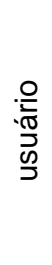 & $\begin{array}{l}\text { estrofes } \\
13 \text { e } 14\end{array}$ & $\begin{array}{c}\text { navegação } \\
\text { - estímulo } \\
\text { resposta }\end{array}$ & associação & ênfase & $\begin{array}{l}\text { narração - } \\
\text { som de } \\
\text { interface - } \\
\text { som } \\
\text { ambiente - } \\
\text { som de } \\
\text { personagens }\end{array}$ & . \\
\hline & & 9 & $\begin{array}{c}\text { escorrer - } \\
\text { buscar - } \\
\text { causar - } \\
\text { querer - } \\
\text { abrigar }\end{array}$ & 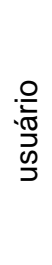 & $\begin{array}{c}\text { estrofe } \\
15\end{array}$ & \begin{tabular}{|c} 
navegação \\
- estímulo \\
resposta - \\
controle \\
de objetos
\end{tabular} & associação & ênfase & $\begin{array}{l}\text { narração - } \\
\text { som } \\
\text { ambiente - } \\
\text { som de } \\
\text { personagens } \\
\text { - som de } \\
\text { interface }\end{array}$ & 윰 \\
\hline & & 10 & $\begin{array}{c}\text { sobreviver - } \\
\text { permitir - } \\
\text { proteger - } \\
\text { passar - } \\
\text { resolver }\end{array}$ & 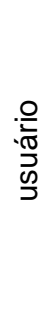 & $\begin{array}{c}\text { estrofe } \\
16\end{array}$ & $\begin{array}{c}\text { navegação } \\
\text { - estímulo } \\
\text { resposta - } \\
\text { controle } \\
\text { de objetos }\end{array}$ & associação & ênfase & $\begin{array}{l}\text { narração - } \\
\text { som } \\
\text { ambiente - } \\
\text { som de } \\
\text { interface - } \\
\text { som de } \\
\text { objetos } \\
\text { interativos }\end{array}$ & 要 \\
\hline & & 11 & $\begin{array}{c}\text { estar (com } \\
\text { medo) - } \\
\text { aumentar - } \\
\text { observar - } \\
\text { levar - ter - } \\
\text { adiantar }\end{array}$ & $\begin{array}{l}\stackrel{0}{\frac{0}{\pi}} \\
\frac{\pi}{50} \\
\frac{0}{5}\end{array}$ & $\begin{array}{l}\text { estrofes } \\
17 \text { e } 18\end{array}$ & \begin{tabular}{|c} 
navegação \\
- estímulo \\
resposta - \\
controle \\
de objetos
\end{tabular} & associação & ênfase & $\begin{array}{l}\text { narração - } \\
\text { som } \\
\text { ambiente - } \\
\text { som de } \\
\text { personagens } \\
\text { - som de } \\
\text { interface - } \\
\text { som de } \\
\text { objetos } \\
\text { interativos }\end{array}$ & $\frac{\pi}{0.0}$ \\
\hline & & 12 & $\begin{array}{c}\text { ajudar - sair } \\
\text { - lixar - } \\
\text { descamar - } \\
\text { matar }\end{array}$ & 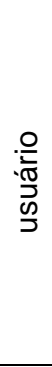 & $\begin{array}{c}\text { estrofe } \\
19\end{array}$ & $\begin{array}{c}\text { navegação } \\
\text { - controle } \\
\text { de objetos }\end{array}$ & associação & ênfase & $\begin{array}{l}\text { narração - } \\
\text { som } \\
\text { ambiente - } \\
\text { som de } \\
\text { personagens } \\
\text { - som de } \\
\text { interface - } \\
\text { som de } \\
\text { objetos } \\
\text { interativos }\end{array}$ & $\frac{\pi}{0}$ \\
\hline & & 13 & $\begin{array}{c}\text { demorar - } \\
\text { cooperar - } \\
\text { instaurar - } \\
\text { carregar }\end{array}$ & $\begin{array}{l}\stackrel{0}{\frac{0}{7}} \\
\stackrel{\frac{\pi}{5}}{5} \\
\frac{9}{3}\end{array}$ & $\begin{array}{l}\text { estrofes } \\
20 \text { e } 21\end{array}$ & $\begin{array}{l}\text { navegação } \\
\text { - estímulo } \\
\text { resposta - } \\
\text { controle } \\
\text { de objetos }\end{array}$ & associação & ênfase & $\begin{array}{l}\text { narração - } \\
\text { som } \\
\text { ambiente - } \\
\text { som de } \\
\text { interface - } \\
\text { som de } \\
\text { personagens }\end{array}$ & : \\
\hline III & 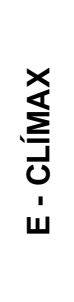 & 14 & $\begin{array}{l}\text { ruivar - } \\
\text { aumentar - } \\
\text { reagir - } \\
\text { chegar }\end{array}$ & 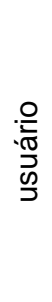 & $\begin{array}{l}\text { estrofes } \\
22 \text { e } 23\end{array}$ & $\begin{array}{c}\text { navegação } \\
\text { - estímulo } \\
\text { resposta - } \\
\text { controle } \\
\text { de objetos }\end{array}$ & associação & ênfase & $\begin{array}{l}\text { narração - } \\
\text { som } \\
\text { ambiente - } \\
\text { som de } \\
\text { interface - } \\
\text { som de } \\
\text { objetos } \\
\text { interativos }\end{array}$ & 霝 \\
\hline
\end{tabular}




\section{CIDI $2017 \quad 8^{\mathrm{m} C I D I}$

\begin{tabular}{|c|c|c|c|c|c|c|c|c|}
\hline & 15 & $\begin{array}{l}\text { ir - surgir - } \\
\text { abrir }\end{array}$ & 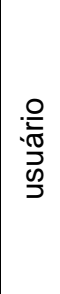 & $\begin{array}{l}\text { estrofes } \\
24 \text { e } 25\end{array}$ & $\begin{array}{l}\text { navegação } \\
\text { - estímulo } \\
\text { resposta - } \\
\text { controle } \\
\text { de objetos }\end{array}$ & associação & ênfase & $\begin{array}{l}\text { narração - } \\
\text { som } \\
\text { ambiente - } \\
\text { som de } \\
\text { interface - } \\
\text { som de } \\
\text { objetos } \\
\text { interativos }\end{array}$ \\
\hline \multirow{2}{*}{ 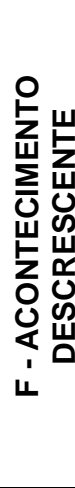 } & 16 & $\begin{array}{l}\text { seguir - } \\
\text { trazer - } \\
\text { deixar }\end{array}$ & $\begin{array}{l}\cdot \frac{0}{\pi} \\
\frac{\pi}{5} \\
\frac{0}{2}\end{array}$ & $\begin{array}{c}\text { estrofe } \\
26\end{array}$ & $\begin{array}{l}\text { navegação } \\
\text { - estímulo } \\
\text { resposta - } \\
\text { controle } \\
\text { de objetos }\end{array}$ & associação & ênfase & $\begin{array}{l}\text { narração - } \\
\text { som } \\
\text { ambiente - } \\
\text { som de } \\
\text { interface - } \\
\text { som de } \\
\text { objetos } \\
\text { interativos }\end{array}$ \\
\hline & 17 & $\begin{array}{c}\text { mudar - } \\
\text { integrar - } \\
\text { fazer - } \\
\text { chegar }\end{array}$ & 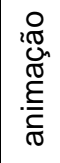 & $\begin{array}{c}\text { estrofe } \\
27\end{array}$ & navegação & associação & encenação & $\begin{array}{l}\text { narração - } \\
\text { som } \\
\text { ambiente }\end{array}$ \\
\hline 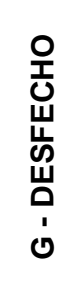 & 18 & $\begin{array}{c}\text { chegar - } \\
\text { abrir } \\
\text { (portas) - } \\
\text { respeitar }\end{array}$ & 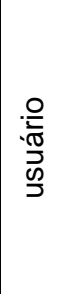 & $\begin{array}{c}\text { estrofe } \\
28\end{array}$ & $\begin{array}{l}\text { navegação } \\
\text { - estímulo } \\
\text { resposta - } \\
\text { controle } \\
\text { de objetos }\end{array}$ & associação & ênfase & $\begin{array}{l}\text { narração - } \\
\text { som } \\
\text { ambiente - } \\
\text { som de } \\
\text { interface - } \\
\text { som de } \\
\text { objetos } \\
\text { interativos }\end{array}$ \\
\hline
\end{tabular}

\section{Desdobramentos da Matriz LIDI}

Com o auxílio da Matriz LIDI, resultado do workshop, a narrativa foi estruturada de forma a servir de escopo para a sequência das etapas seguintes de projeto. Assim, partiu-se então para a fase criativa com concepção de personagens, painéis de referência e ilustração das cenas aliadas a arquitetura da informação e wireframes.

Figura 9 - Storyboard com esboços incluídos. Fonte: elaborado pelos autores.

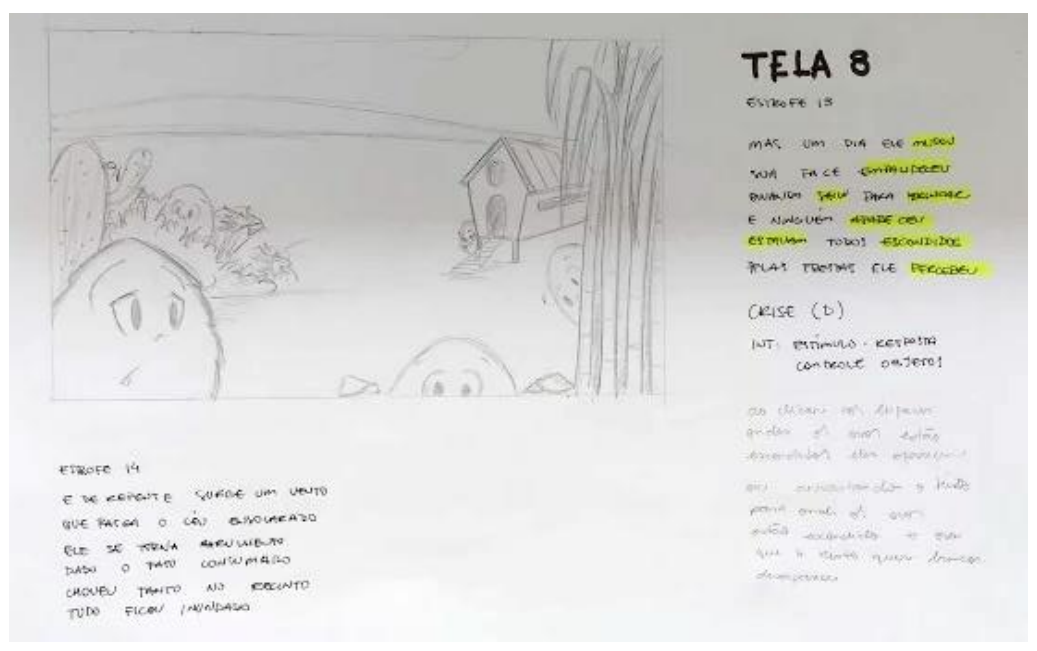




\section{CIDI 2017 告" col

Figura 10 - Evolução da etapa criativa com desenvolvimento dos wiframes até as telas finais para o projeto do book app "O Vizinho Diferente". Fonte: elaborado pelos autores.
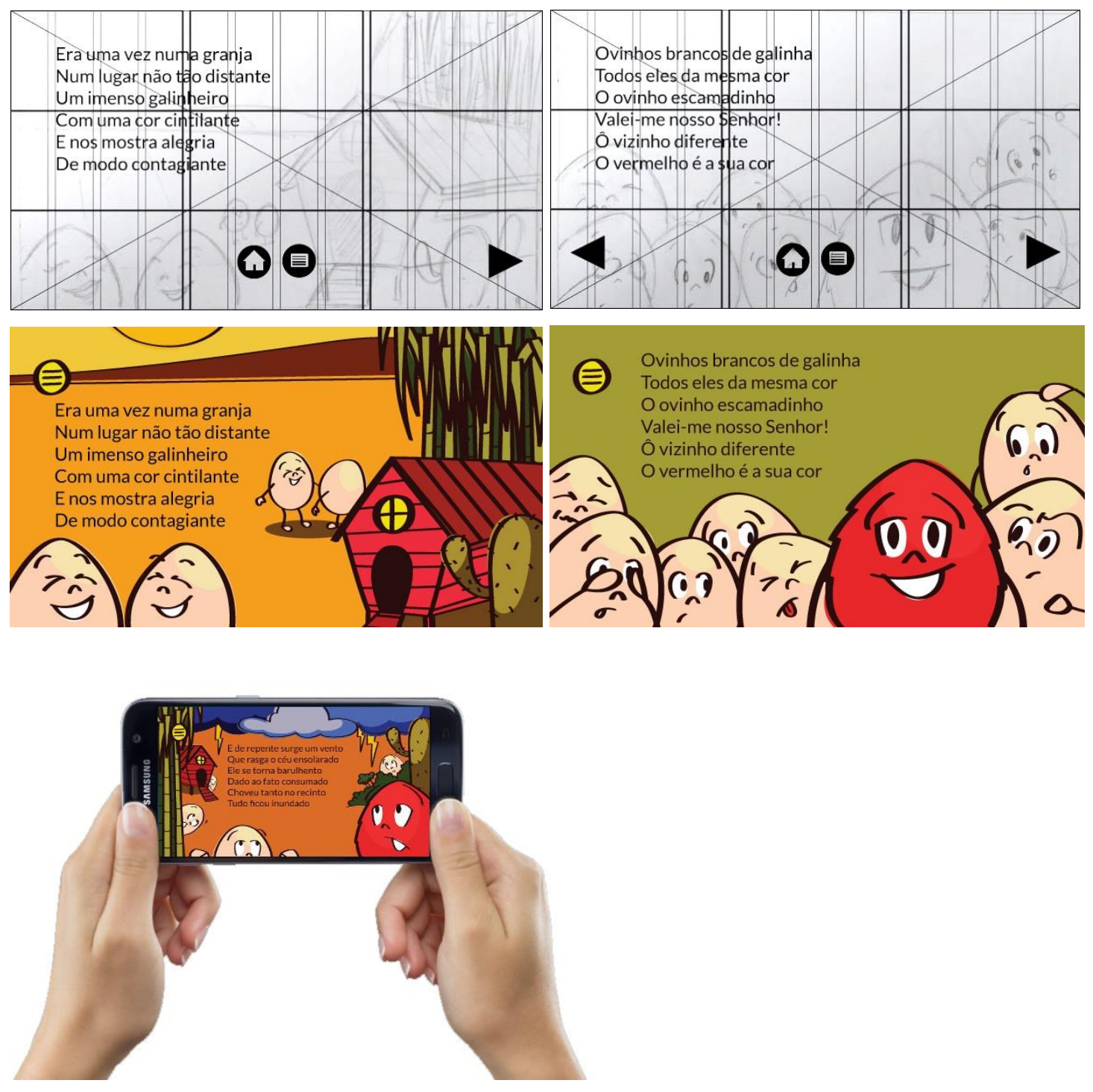

Foi realizado outro storyboard para o desenvolvimento dos esboços das telas, sendo incluidas nele as informações da Matriz. Dessa forma, procurou-se integrar todos os aspectos de cada tela. Avançando, foi desenvolvido os wireframes, as ilustrações foram vetorizadas até se chegar as telas finais do aplicativo.

\section{Conclusão}

Concluiu-se que a Matriz LIDI é útil como ferramenta de apoio ao design de mídias e interatividade para o book app infantil. Além disso, encaminha o projeto para explorar os recursos tecnológicos em função da narrativa, de acordo com premissas apontadas.

Destaca-se a contribuição do workshop por seu caráter colaborativo. Sua validade foi construtiva por acontecer antes da elaboração da ficha de conteúdo e storyboard. Assim, não haviam ideias limitadoras, tendo-se, portanto, liberdade para explorar caminhos. Entretanto, não sendo possível essa abordagem pode-se realizar esses trabalhos internamente.

O processo de organizar a expressão hipermídia em um storyboard mostrou-se eficiente tanto para organizar as informações quanto para agilizar o preenchimento da Matriz. Também 
foi útil por já se ter incluído anotações de ideias para a ilustração. Dessa maneira, integrou-se texto, imagem, mídias e interatividade facilitando as etapas seguintes até as ilustrações finais.

Cabe ressaltar que a Matriz é elaborada no início do projeto, mas ao longo do processo pode sofrer alterações. Entretanto, sua contribuição se mantém e demonstra que ela é uma ferramenta que não engessa o projeto, mas sim dá rumo a ele. Ela funcionou de escopo para as etapas de projeto seguintes.

\section{Referências}

BOLOGNA CHILDREN'S BOOK FAIR. Bologna Ragazzi Digital Award. Disponível em: < http://www.bookfair.bolognafiere.it/en/bologna-ragazzi-digital-award/1034.html >. Acesso em: 16. ago. 2015.

CHARTIER, Roger. A aventura do livro: do leitor ao navegador. Tradução Reginaldo de Morais. São Paulo: Unesp, 1999.

CHATMAN, Seymour Benjamin. Story and discourse: Narrative structure in fiction and film. Londres: Cornell University Press, 1980.

DE OLIVEIRA SOBREIRA, Rogério; DE ALMEIDA, Anselmo Guerra. Música e Cena. Arte da Cena (Art on Stage), v. 1, n. 2, p. 51-66. DOI: 10.5216/ac. v1i2.34769. Goiania, 2015.

DIGITAL BOOK AWARDS. The digital Book Awards. Disponível em: $<$ http://www.digitalbookworld.com/the-digital-book-awards/>. Acesso em: 16. ago. 2014. 2011.

FRASCARA, Jorge. ¿Qué es el diseño de la información? 1.ed. Buenos Aires: Infinito,

HASLAM, Andrew. O livro e o designer II: como criar e produzir livros. São Paulo: Rosari, 2007.

HOROWITZ, Steve; LOONEY, Scott R. The Essential Guide to Game Audio: The Theory and Practice of Sound for Games. Londres: CRC Press, 2014.

LINDEN, Sophie Van der. Para ler o livro ilustrado. São Paulo: Cosac Naif, 2011.

LAUREL, Brenda. Computers as theatre. 2.ed. Crawfordsville Indiana: Pearson/Addisonwesley, 2014.

MILLER, Carolyn Handler. Digital storytelling: A creator's guide to interactive entertainment. Taylor \& Francis, 2014.

MORAES, Ana Maria; SANTA ROSA, José Guilherme. Design participativo, técnicas para inclusão de usuários no processo de ergodesign de interfaces. Rio de Janeiro: Rio Book's, 2012.

PIMENTA, Sherline; POOVAIAH, Ravi. On defining visual narratives. IDC Design Research Journal, v 3, p 25-46, 2010 sponív I m: <http://www.idc.iitb.ac.in/resources/dt-aug2010/On\%20Defining\%20Visual \%20Narratives.pdf>. Acesso em: 13. mar. 2014.

TEIXEIRA, Deglaucy J. A interatividade e a narrativa no livro digital infantil: proposição de uma matriz de análise. Dissertação (Mestrado) - Programa de Pós-Graduação em Design e Expressão Gráfica, Universidade Federal de Santa Catarina. Florianópolis, 2015.

TEIXEIRA, Deglaucy Jorge; MARITAN, Bruna Bertolazi; GONÇALVES, Berenice S. Um modelo de fluxo para design de livro digital infantil. Blucher Design Proceedings, v. 3, n. 1, p. 78-85, 2016.

YOKOTA, Junko; TEALE, William H. Picture Books and the Digital World. The Reading Teacher, v. 67, n. 8, p. 577-585. 2014.

Sobre o(a/s) autor(a/es)

Bruna Bertolazi Maritan; Graduanda, UFSC, Brazil <brunabertolazi@gmail.com> 
Berenice S. Gonçalves; Doutora, UFSC, Brazil <berenice@cce.ufsc.br>

Deglaucy Jorge Teixeira; Doutorando, UFSC, Brazil <deglaucyjorge@gmail.com> 